Postprint: Roels S, Janssen H, 2006. A comparison of the Nordtest and Japanese test methods for the moisture buffering performance of building materials, Journal of Building Physics, 30, 137-161.

doi: 10.1177/174425910606810

\title{
A COMPARISON OF THE NORDTEST AND JAPANESE TEST METHODS FOR THE MOISTURE BUFFERING PERFORMANCE OF BUILDING MATERIALS
}

\author{
StAF RoELs *AND HANS JANSSEN \\ Laboratory of Building Physics \\ Catholic University of Leuven \\ Kasteelpark Arenberg 40, B-3001 Leuven, Belgium
}

* author to whom correspondence should be addressed. E-mail: staf.roels@bwk.kuleuven.be

\begin{abstract}
Two test methods, one worked out in a Nordtest-project, and the other available as Japanese Industrial Standard, both developed to characterise building materials with respect to moisture buffering performance, are analysed in detail by a numerical study on four different materials. Both test methods are based on a similar kind of dynamic loading, but the specifications of each test protocol vary. Therefore, the sensitivity of the test protocols is investigated by varying different protocol parameters. Subsequently, the practical applicability of the obtained values is investigated by confronting the values obtained for the four materials with the dynamic response of a small room with each of the materials used in turns as finishing material. Finally, the results determined according to the dynamic test protocol are compared with values calculated from steady state material data.
\end{abstract}

KEY WORDS: moisture buffering, moisture buffer value, hygric response, dynamic loading

\section{INTRODUCTION}

Indoor relative humidity in dwellings and office buildings has been investigated for a long time already. Earlier studies mainly attempted to classify buildings with respect to indoor relative humidity, or focussed on isolated effects, such as the influence of indoor relative humidity on comfort and indoor air quality, the effect of moisture on energy consumption, the indoor relative humidity as boundary condition for mould growth and durability of the building envelope, etc. (e.g. Hens, 1992; Fang et al., 1998; Clausen et al., 1999; Seldbauer and Krus, 2003; Kalamees et al., 2006). More recently, researchers tried to come to an integrated approach (Simonson et al., 2002, Hens 2003, Rode et al., 2003). One of the active topics of research in this integrated approach is the passive control of indoor relative humidity variations by use of the moisture buffering capacities of (finishing) materials. Many authors refer to the possibilities of building materials to reduce peaks in indoor humidity variations, based on measurements (Padfield, 1999; Rode et al., 2002; Simonson et al., 2004a) or simulations (Rode and Grau, 2002; Simonson et al., 2004b). Although, to come to a practical applicability of building materials as humidity regulators, a simple but unambiguous characterisation of building materials is necessary. So far, appraisal of the moisture buffering quality of building materials was based on a variety of definitions. A uniform characterisation, that e.g. can be used in the design phase to compare different building materials, was lacking. Only recently two attempts were made to come to a clear guideline and a standard procedure to characterise building materials with respect to moisture buffering: a Japanese industrial standard describing a "test method of ad/desorption performance of building materials to regulate indoor humidity" (JIS A 1470-1, 2002), and a proposal for a test protocol developed in the Nordtest-project on moisture buffering of building materials (Report BYG DTU R-126, 2005).

Both isothermal test methods are based on dynamic climatic chamber tests, where a specimen is subjected to environmental changes in relative humidity according to a step or a square wave signal. Beforehand, the specimen is preconditioned until it reaches a constant weight (hygroscopic equilibrium with the environment) and is sealed on all but one or two surfaces. But, though similar in set-up, both test methods also show some important differences, such as time scheme and levels of the imposed signal, required specimen thickness and expression of the results.

Aim of this paper is to investigate the reliability of the proposed test protocols and the practical applicability of the results as a characterising value for moisture buffering performance. Both issues are studied numerically on four different materials. Beforehand, both test proto- 
cols are compared. Then, starting from the observed similarities and differences, the sensitivity of the proposed dynamic test method is investigated by varying parameters as the time scheme of the imposed signal, the thickness of the material layer and the surface film resistance. In the next paragraph, the obtained values for the different materials are confronted with the dynamic response of a small room - both for daily as for short term variations - with each of the materials used in turns as finishing material for the walls. Finally, as sometimes a discrepancy between dynamically measured data and material properties measured under steady state conditions is mentioned (e.g. Peuhkuri et al., 2004; Rode et al., 2005), the results determined according to the dynamic test protocol are compared with values calculated from steady state material data making use of the analytic solution for the imposed signal.

\section{COMPARISON OF THE TEST PROTOCOLS}

The Japanese Industrial Standard and the test protocol developed in the Nordtest-project are very similar, both in objectives and measurement principles. Both test methods want to quantify the moisture adsorption/desorption capabilities of building materials, in relation to passive indoor humidity control. In either case a specimen is subjected to a step or square wave relative humidity signal and the weight change of the specimen is logged, while temperature is kept constant at $23^{\circ} \mathrm{C}$. But, further details of both methods differ in imposed signal, thickness of specimen and report of data.

The Japanese Industrial Standard (JIS) makes a distinction between a step signal, in the standard referred to as 'moisture adsorption/desorption test', and a square wave signal, referred to as 'periodically regular moisture adsorption/desorption test'. In both cases a $48 \mathrm{~h}$ scheme is imposed: 24 hours of high relative humidity followed by 24 hours of low relative humidity. Three levels of humidity conditions are proposed: a low humidity level between 53 and $33 \% \mathrm{RH}$, a middle humidity level between 75 and $53 \% \mathrm{RH}$ and a high humidity level between 93 and $75 \% \mathrm{RH}$. As a rule the specimen thickness has to be the thickness of the product. After curing, all surfaces of the specimen are sealed vapour tight with an aluminium sheet except the moisture adsorption/desorption surface. Specific attention has to be paid to the surface film resistance during the test. The air flow on the surface of the specimen has to be adjusted so that the surface film resistance measures $4.8^{\star} 10^{7} \pm 10 \% \mathrm{~m}^{2} \mathrm{sPa} / \mathrm{kg}$. To set the air current, a calibration procedure based on cup tests with one and two layers of drawing paper has to be followed. The test results are reported as moisture adsorption/desorption masses, and as the evolution of moisture content with time. For the step signal also the time evolution of the rate of moisture uptake and release has to be given.

In the test protocol of the Nordtest-project an asymmetric square wave signal is proposed, with different intervals for uptake and release. Moisture uptake and release are measured on specimen exposed to a high relative humidity (75\%) during 8 hours, followed by a 16 hours period of low relative humidity (33\%). The data are reported as Moisture Buffer Value (MBV) by normalising the uptake value per exposed surface area and change in relative humidity. The unit of $\mathrm{MBV}$ is $\mathrm{kg} /\left(\mathrm{m}^{2} . \% \mathrm{RH}\right)$. For the specimen thickness the test protocol permits two options: the thickness as in the intended practical application, or a thickness larger than the $1 \%$ penetration depth for daily humidity variations. Concerning the surface film resistance a similar option is taken as in the Japanese Industrial Standard. The test protocol of the Nordtest-project aims to imitate a normal indoor environment with air velocities around $0.10 \pm 0.05$ $\mathrm{m} / \mathrm{s}$ inside the test chamber, which should correspond to a surface film resistance of $5.0^{\star} 10^{7}$ $\mathrm{m}^{2} \mathrm{sPa} / \mathrm{kg}$. However, a test procedure to determine the surface film resistance is not given.

\section{MATERIALS INVESTIGATED}

The reliability and the practical applicability of the test methods is investigated numerically for four materials: wood fibreboard (WFB), plywood (PW), gypsum plaster (GP) and aerated cellular concrete (ACC). Those four materials were chosen because of their differences in water vapour permeability and sorption isotherm, in such way that a different penetration depth and dynamic response could be expected. Material data of plywood and wood fibreboard were obtained from Kumaran (1996). For the gypsum plaster the sorption isotherm and cup tests results determined by Goossens (2003) were used. The data for ACC are taken from Peuhkuri (2003). Note that in the current study hysteresis on the sorption isotherm is not considered critical and is thus not taken into account. Figure 1 shows both the sorption isotherm in moisture content $w\left(\mathrm{~kg} / \mathrm{m}^{3}\right)$, and the water vapour resistance factor $\mu(-)$ as a function 
of relative humidity for the four materials. To use the measured data in the numerical modelling, sorption isotherm and vapour resistance factor are described by an analytic function of the form:

$$
\begin{aligned}
& w=w_{\text {sat }}\left(1+(m \cdot \ln (\Phi))^{n}\right)^{(1-n) / n} \\
& \mu=\frac{1}{a+b e^{c \Phi}}
\end{aligned}
$$

with $\Phi(-)$ the relative humidity and $w_{s a t}, m, n$ and $a, b$ and $c$ parameters. The parameters of the analytic fit for the different materials are given in Table 1 . The fitted curves are also presented as the continuous lines on Figure 1. Table 1 also gives the penetration depths for

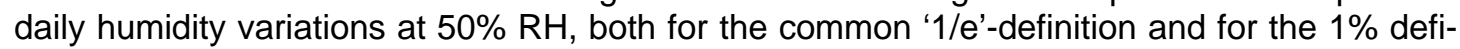
nition adopted in the Nordtest-project. As the 1/e-definition, the 1\%-definition refers to the depth in the specimen where the amplitude has reduced to $1 \%$ of the surface amplitude. Note the important difference in penetration depth between the four materials: PW around 1 $\mathrm{mm}(5 \mathrm{~mm})$, WFB almost $7 \mathrm{~mm}(29 \mathrm{~mm})$, ACC $15 \mathrm{~mm}(70 \mathrm{~mm})$ and GP more than $30 \mathrm{~mm}$ $(140 \mathrm{~mm})$ for the $1 / \mathrm{e}$ and $1 \%$ penetration depth respectively.

\section{SENSITIVITY ANALYSIS OF THE DYNAMIC TEST METHOD}

Although both test methods use a similar kind of dynamic loading to characterise building materials with respect to indoor moisture buffering, the specification of each test protocol differs in time scheme and levels of the imposed signal, required specimen thickness, requirements for air current setting in the climatic chamber, etc. as was shown in section 2 . Therefore, the influence of these parameters on the characterisation of materials is numerically investigated for the four materials. To do so the test protocol of the Nordtest-project is taken as starting point. This allows an easy comparison of the influence of each parameter on the obtained results, making use of the moisture buffer value (MBV).

\subsection{Influence of the specimen thickness}

Whereas the Japanese Industrial Standard requires the specimen thickness to be equal to the thickness of the product, the Nordtest-project also allows measurements on specimen with a thickness larger than the $1 \%$ penetration depth for daily humidity variations. However, one can expect that in reality this requirement will not be checked for the simple reason that, in most cases, the penetration depth will not be known. For a lot of materials moreover, like finishing boards, the product is commercially available in different thicknesses. Therefore, to investigate the influence of the specimen thickness on the obtained MBV, the dynamic response according to the test protocol was numerically predicted with the specimen thickness as parameter. Ten cycles of 8 hours of $75 \% \mathrm{RH}$ followed by 16 hours of 33\% RH, have been simulated and for all four materials the MBV is determined on the results for the last day. All simulations were done for the prescribed surface film resistance of $5.0^{\star} 10^{7} \mathrm{~m}^{2} \mathrm{sPa} / \mathrm{kg}$. Table 2 shows the results. As soon as the specimen thickness is less than the 1/e penetration depth for daily humidity variations (respectively $0.69 ; 1.52$ and $3.33 \mathrm{~cm}$ for WFB, ACC and GP), the obtained MBV's drop. This is most pronounced for gypsum plaster where the ' $0.5 \mathrm{~cm}$ ' MBV is only $25 \%$ of the ' $10 \mathrm{~cm}$ ' value. This implies that the Nordtest option to allow specimen with penetration depth thickness may lead to non-representative results.

When comparing Tables 1 and 2, it can furthermore be concluded that the 1/e penetration depth seems more appropriate to evaluate the thickness of a specimen than the more severe $1 \%$ penetration depth as used in the Nordtest-project.

Note in Table 1, that also some small differences are found in the obtained MBV's even when the specimen thickness is larger than the 1/e penetration depth. These result from the fact that the thickness of the sample will also influence the mean relative humidity over the sample.

4.2. Influence of the time scheme of the imposed signal

One of the biggest differences between the JIS and the test protocol proposed by the Nordtest-project is the imposed time scheme of the $\mathrm{RH}$-signal. Whereas the JIS proposes a 48 hours scheme with 24 hours of high $\mathrm{RH}$ followed by 24 hours of low $\mathrm{RH}$, the Nordtest-project proposes an asymmetric 24 hours scheme: 8 hours of high RH followed by 16 hours of low 
$\mathrm{RH}$. The influence of the time scheme on the dynamic response of the specimen is numerically investigated for all four materials, for specimen with a thickness of $1 \mathrm{~cm}$ and $10 \mathrm{~cm}$. All simulations are performed with the prescribed surface film resistance of $5.0^{*} 10^{7} \mathrm{~m}^{2} \mathrm{sPa} / \mathrm{kg}$. The results, expressed as MBV's, are presented in Table 3. The MBV's obtained with the 48 hours JIS scheme are - for the materials investigated - systematically about a factor 1.5 higher than the MBV's determined according to the Nordtest-project, except when the specimen thickness is less than the 1/e penetration depth. The latter is the case for the $1 \mathrm{~cm}$ specimens of ACC and GP. In that case both time schemes give almost the same results. This can easily be explained when plotting the change in moisture content for both time schemes as a function of time. Figure 2 shows these graphs for WFB and GP. For thin specimen, with the thickness below the 1/e penetration depth (e.g. $1 \mathrm{~cm}$ of GP), hygroscopic equilibrium with the surrounding $\mathrm{RH}$ is obtained in both time schemes within the loading branch and hardly any difference will be found in the obtained MBV's. This implies that, while aiming at a similar characterisation, the JIS and Nordtest protocols will arrive at different relative assessments of the moisture buffering performance of materials.

\subsection{Influence of the surface film resistance}

Whereas the JIS describes a calibration method for the surface film resistance, the Nordtest protocol only prescribes the air speed around the sample. Since the surface film resistance is not only determined by the air speed, but also by the measurement geometry, this implies that the surface film resistance may be different from the desired $5^{\star} 10^{7} \mathrm{~m}^{2} \mathrm{sPa} / \mathrm{kg}$. To analyse the influence of such differences, the surface film resistance in the simulations is varied between $3.3^{\star} 10^{4} \mathrm{~m}^{2} \mathrm{sPa} / \mathrm{kg}$ (a more theoretical case with a very low value in a way that the effect of the boundary layer can be neglected) towards $3.3^{\star} 10^{8} \mathrm{~m}^{2} \mathrm{sPa} / \mathrm{kg}$ (a rather high value - even for indoor conditions - corresponding to hardly any air flow above the specimen). Simulations are performed for all four materials and for six different values of the surface film resistance. To exclude effects from limited specimen thicknesses, all specimens were supposed to be 10 $\mathrm{cm}$ thick. Table 4 gives an overview of the obtained MBV's for the four materials. Figure 3 shows the predicted influence of the surface film resistance on the hygric response of a sample of wood fibre board. For wood fibre board, which is a rather vapour open material with a high moisture capacity, the difference in surface film resistance results in a $\mathrm{MBV}_{33-75 \%}$ varying between 2.31 and $0.55 \mathrm{~g} /\left(\mathrm{m}^{2} . \% \mathrm{RH}\right)$. The biggest difference occurs when going to very high surface film resistances. Note the sudden drop in MBV when increasing the surface film resistance from $1^{*} 10^{8}$ to $3.3^{*} 10^{8} \mathrm{~m}^{2} \mathrm{sPa} / \mathrm{kg}$. As indicated in Table 4 the influence on the other materials is less, but far from negligible, even for small deviations from the desired $5^{\star} 10^{8}$ $\mathrm{m}^{2} \mathrm{sPa} / \mathrm{kg}$. Note also that, though the surface film resistance has hardly any influence on the sequence of the materials with respect to the MBV, it does change the relative proportion of the MBV's. E.g. for a surface film resistance of $5^{\star} 10^{7} \mathrm{~s} / \mathrm{m}$ (comparable to the requirements of the test methods) the MBV of wood fibre board is 2.7 times larger than that of plywood, while for the theoretical case with a negligible surface film resistance the proportion is 3.04. As will be shown in section 6 , the surface film resistance may also be one of the reasons for the deviation between dynamically measured values and values calculated from steady state material data.

\section{RELIABILITY OF THE RESULTS FOR PRACTICAL APPLICATIONS}

To investigate whether the proposed test protocols are indeed reliable methods to predict and quantify the hygric buffering capacity of materials in real situations, the MBV of the different materials are confronted with the dynamic hygric response of a small room with each of the materials used in turns as available hygric buffering material. Therefore, numerical simulations are performed both for long term (daily) and short term variations of the $\mathrm{RH}$ inside the room.

\subsection{Numerical simulations of the moisture balance of a small room}

In the numerical simulations the hygric response of a small room of $90 \mathrm{~m}^{3}$ is analysed. In the room the walls are assumed to be finished with one of the four materials investigated, with a total absorbing area of $60 \mathrm{~m}^{2}$. Each calculation is performed for a period of ten days. Each day a constant scheme of moisture production is imposed. For the long term variations a moisture production of $300 \mathrm{~g} / \mathrm{h}$ is assumed every first eight hours of the day, followed by a period of 16 hours without moisture production. For the short term variations, a scheme of 
one hour with a moisture production of $600 \mathrm{~g} / \mathrm{h}$ is followed by five hours without moisture production, and this four times a day. Assuming that the only coupling between indoor climate and outside climate is the ventilation of the room with outside air, that no other hygroscopic materials are present and that the temperature dependency of the air density can be neglected, the moisture balance of the room can be written as:

$$
\frac{\partial \rho_{v i} V}{\partial t}=\left(\rho_{v e}-\rho_{v i}\right) \frac{n V}{3600}+G_{v p}-A q_{b u f}
$$

with $\rho_{v i}\left(\mathrm{~kg} / \mathrm{m}^{3}\right)$ the water vapour concentration inside, $\rho_{v e}\left(\mathrm{~kg} / \mathrm{m}^{3}\right)$ the water vapour concentration outside, $V\left(\mathrm{~m}^{3}\right)$ the volume of the room, $n\left(\mathrm{~h}^{-1}\right)$ the ventilation rate taken at 0.5 per hour, $G_{v p}(\mathrm{~kg} / \mathrm{s})$ the vapour production inside the room, $A\left(\mathrm{~m}^{2}\right)$ the surface available for hygroscopic buffering and $q_{\text {buf }}\left(\mathrm{kg} / \mathrm{m}^{2} \mathrm{~s}\right)$ the water vapour exchange with this absorbing surface. The latter is calculated with a finite element model to analyse the coupled heat and moisture transport in building enclosures, with the relative humidity inside the room as boundary condition. Each time step the inside relative humidity is updated by solving Equation (3) implicitly. To avoid that outside climatic conditions would disguise the hygric response of the room, no real climatic data are used, but instead the outside boundary conditions are kept constant at $10^{\circ} \mathrm{C}$ and $65 \% \mathrm{RH}$. The interior surface film resistance for vapour transfer is taken at $5.0^{\star} 10^{7}$ $\mathrm{m}^{2} \mathrm{sPa} / \mathrm{kg}$. The inside temperature is kept constant at $20^{\circ} \mathrm{C}$.

\subsection{Results for long term (daily) variations}

In the simulations with long term variations, the periods with and without vapour production have the same length as the steps of the signal in the test protocol of the Nordtest-project to determine the MBV. Though, the relative humidity inside is now no longer imposed as a square wave signal, but instead the indoor $\mathrm{RH}$ will gradually increase during the eight hours of moisture production, followed by a gradual decrease during the intermediate 16 hours without moisture production. To compare the influence of the type of finishing material on the inside $\mathrm{RH}$, a reference simulation has been performed in which no absorbing material was present. Furthermore, for each of the four materials, two simulations were performed, once with a $1 \mathrm{~cm}$ and once with a $10 \mathrm{~cm}$ material thickness. Figure 4 shows for the last day the response of relative humidity inside the room for the different configurations in case of a (hypothetical) $10 \mathrm{~cm}$ thick layer. Figure 5 shows the same results if only a $1 \mathrm{~cm}$ thick layer is applied.

If the materials are applied with a thickness of $10 \mathrm{~cm}$ (Figure 4), one can notice that all four materials are significantly reducing the relative humidity variation inside the room compared to the reference case when no hygroscopic material is present. The strongest reduction is found for wood fibreboard, which is able to bring back the original $\mathrm{RH}$-amplitude of $18.5 \%$ to a value of $7.0 \%$. Comparing the amplitudes in the room found for the four materials with the Nordtest moisture buffer values as determined on $10 \mathrm{~cm}$ thick specimen (see Table 5), a good correlation is found.

Looking at the evolution of the relative humidity inside the room in case the materials are applied with a thickness of only $1 \mathrm{~cm}$ (Figure 5), the response of the room with wood fibreboard and plywood is almost identical as when the materials are applied with a thickness of $10 \mathrm{~cm}$. For the rooms with aerated cellular concrete and gypsum plaster, however, the hygric buffering in case of a $1 \mathrm{~cm}$ layer is much less than with a $10 \mathrm{~cm}$ layer and the room with the gypsum plaster as finishing material shows now the highest amplitude instead of the one with plywood as finishing material. This results from the fact that for gypsum plaster $1 \mathrm{~cm}$ is below the 1/e penetration depth for daily humidity variations. Because of that, the MBV determined on samples with a thickness larger than the penetration depth (one of the options in the Nordtest protocol) is no good indication for the buffering capacities of the finishing layer. This can clearly be illustrated if we plot the amplitude of the relative humidity in the room as a function of the moisture buffer value (Figure 6, left side). If the penetration depth is larger than the applied thickness, as is the present case for gypsum plaster, different points will be obtained without a correlation between MBV and amplitude. When the amplitudes are plotted as a function of the moisture buffer values determined according to the Japanese Industrial Standard, which means on specimen of the same thickness as applied in the room, but with different time scheme (see Figure 6, right side), a much better correlation is found. The best agreement, however, is obtained if the MBV is determined according to a loading protocol which is in close agreement with the moisture conditions of the room. For the current case it means: time scheme according to the Nordtest-project and surface film resistance and 
specimen thickness as in the room (Figure 6, middle). Now, a nice descending curve is found between MBV and indoor RH amplitude.

\subsection{Results for short term variations}

Compared to the previous simulations the vapour production rate is doubled $(600 \mathrm{~g} / \mathrm{h}$ instead of $300 \mathrm{~g} / \mathrm{h}$ ), but lasts a shorter period. Every day shows now four peaks of vapour production, each of one hour followed by five hours without vapour production. Again two simulation rounds are performed with the thickness of the absorbing material layer as variable. Figure 7 shows the results for the last 6 hours of the last day, in case the materials are applied with a thickness of $10 \mathrm{~cm}$, Figure 8 if applied with a thickness of $1 \mathrm{~cm}$. The continuous lines without dots on the figures correspond to the reference case when no hygroscopic material is present. Table 6 compares again the amplitudes in the room with the moisture buffer values of the materials as determined according to the Nordtest-protocol on 1 and $10 \mathrm{~cm}$ thick specimen.

Also for the short term variations wood fibreboard (with the highest MBV) gives the strongest reduction in indoor $\mathrm{RH}$ amplitude, followed by gypsum plaster, cellular concrete and plywood. Figure 9 plots, as for the daily variations, the obtained $\mathrm{RH}$-amplitude inside the room as a function of the moisture buffer value of the materials: at the left side for the MBV determined according to the Nordtest-protocol but on $10 \mathrm{~cm}$ thick specimen, in the middle for the MBV determined according to the Nordtest-protocol, but now with the specimen thickness as applied in the room and at the right side for the MBV determined according to the JIS (with the correct specimen thickness). As also shown in Table 6, for all three cases a rather poor correlation between MBV and indoor $\mathrm{RH}$ amplitude is found.

This implies that the test protocols, based on long term variations, are primarily useful as a characterisation of materials when analysing similar term hygric buffering. Both the Nordtestproposal with the 8-16 hours scheme and the Japanese Industrial Standard with the 24-24 hours scheme seem less appropriate to appreciate the hygric buffering capacities for short term variations.

\section{DYNAMICALLY DETERMINED RESULTS VERSUS STEADY STATE DERIVED RESULTS}

As an alternative to the dynamic test protocol, the MBV may, under certain conditions, also be calculated from the sorption isotherm and cup test results. Rode et al. (2005), however, claim that there might be a disagreement between measured and calculated moisture buffer values, due to the dynamic feature of the test protocol, whereas the sorption isotherm and water vapour diffusion coefficient are obtained under steady state conditions. In this section the dynamically determined results of $\S 4$ are compared with steady state derived results.

For such comparison the surface excitation of a semi-infinite specimen is commonly accepted as theoretical model (Künzel and Kiessl, 1990; Wadsö, 1993; Peuhkuri et al., 2004). When the surface vapour pressure of a semi-infinite specimen with linear material properties is varied along a rectangular wave pattern - a non-symmetric periodic step change between a high and low value - the moisture accumulation during the upload phase can be calculated as (Carslaw and Jaeger, 1990):

$$
G(t)=k b_{m} \Delta p_{v, s} \sqrt{t}
$$

with $G\left(\mathrm{~kg} / \mathrm{m}^{2}\right)$ the moisture accumulation, $k(-)$ a proportionality constant depending on the shape of the rectangular wave, $b_{m}$ the moisture effusivity of the material, $\Delta p_{v, s}(\mathrm{~Pa})$ the difference between the high and low surface vapour pressure and $t$ the time. For the Nordtest 8-16 hours scheme, and the JIS $24-24$ hours scheme, $k$ respectively equals 0.984 and 0.856 . The moisture effusivity, expressed in $\mathrm{kg} /\left(\mathrm{m}^{2} \cdot \mathrm{Pa} \cdot \mathrm{s}^{0.5}\right)$, is defined as:

$$
b_{m}=\sqrt{\delta_{p} \frac{\partial w}{\partial p_{v}}}
$$

with $\delta_{p}(\mathrm{~s})$ the water vapour permeability, $w\left(\mathrm{~kg} / \mathrm{m}^{3}\right)$ the moisture content and $p_{v}(\mathrm{~Pa})$ the vapour pressure.

Given that:

1. the specimen's thickness is far larger than the penetration depth for daily humidity variations, and can thus be seen as semi-infinite for the imposed signal; 
2. the non-linearity of the material properties is negligible in the $\mathrm{RH}$-range under consideration;

3. the surface film resistance is negligible in comparison with the internal vapour transfer resistance;

the MBV may be derived from the steady state sorption isotherm and cup test data:

$$
M B V=0.01 k p_{v, \text { sat }} b_{m} \sqrt{t_{\text {upload }}}
$$

with $p_{v, \text { sat }}$ the saturation vapour pressure and $t_{\text {upload }}$ the upload interval.

Figure 10 compares the dynamically determined MBV - simulated with the Nordtest protocol, with a $10 \mathrm{~cm}$ specimen thickness and a negligible surface film resistance - to such steady state derived MBV (Eq. 6). It has to be noted that the non-linear hygric properties cause the latter to be continuously variable with the relative humidity, while the former are considered as a constant over the $33 \% \mathrm{RH}$ to $75 \% \mathrm{RH}$ interval.

For all four materials, a rather good agreement can be observed around $54 \% \mathrm{RH}$ (mean value of the test protocol). Although, the exact intersections of the dynamically determined and the steady state derived values are situated at different $\mathrm{RH}$ for the four materials (indicated by the arrows on Figure 10). This can almost certainly be attributed to violations of the second condition: the non-linearity of the hygric properties is not entirely negligible. Consequently, accurate computation of the MBV from the steady state sorption isotherm and cup test data is less straightforward as often presented, as it is not clear at which RH the moisture effusivity (and $\mathrm{MBV}$ ) has to be calculated. Figure 10 does indicate though that the test protocol's mean RH will yield acceptable first estimates.

Neither the Nordtest, neither the JIS measurement protocol do however correspond with the surface excitation of a linear semi-infinite material, required for agreement between dynamically determined and steady-state derived MBV. The limited surface film resistance and eventually the limited specimen thickness violate the aforementioned condition 1 and 3 . Consequently the required proportionality between the moisture accumulation and square root of time (Eq. 4) is no longer satisfied, and the dynamically determined MBV are bound to differ from the steady state derived values (Eq. 6). This illustrated in Figure 11, which depicts the moisture accumulation of gypsum plaster in function of the square root of time, for the 8 hour upload phase of the Nordtest protocol.

Figure 11 demonstrates that, when the specimen can be assumed semi-infinite and the surface film resistance can be considered negligible, the moisture accumulation proceeds linearly with the square root of time, as predicted by Equation (4). It was shown in Figure 10 that the thus dynamically determined MBV corresponded nicely with steady state derived MBV. Figure 11 also shows though that a realistic surface film resistance and a limited specimen thickness disturb the square root of time behaviour. The surface film resistance leads to an initial off-set, and the limited specimen thickness results in a premature deflection of the moisture accumulation. Both effects are combined when testing a specimen with limited thickness and surface film resistance. Previously reported differences between dynamically determined and steady state derived values (Peuhkuri et al., 2004, Peuhkuri and Rode, 2005) can hence most probably be attributed to a mismatch between the experimental and theoretical conditions.

While it has been opted here to modify the 'experimental' conditions according to the requirements of the analytical model, Carslaw and Jaeger (1990) also provide more advanced analytical models, incorporating a realistic surface film resistance and a finite specimen thickness, allowing to match analytical models to the Nordtest and JIS experimental conditions.

\section{CONCLUSION AND DISCUSSION}

Two test methods, one worked out in a Nordtest-project, and the other available as Japanese Industrial Standard, both developed to characterise the hygric buffering capacities of building materials, were compared and their practical applicability was investigated. Both test methods showed to be very similar both in objectives and measurement principles. The specifications of each test protocol, however, differ in time scheme, levels of the imposed signal and required specimen thickness. To investigate the influence of these parameters on the characterisation of materials, numerical simulations have been performed for four different materials: wood fibre board, plywood, aerated cellular concrete and gypsum plaster.

The specimen thickness showed to be very important once less than the 1/e penetration depth for daily humidity variations. At that moment a sudden drop in obtained moisture buffer values was observed. Also the time scheme of the imposed signal showed to be most signifi- 
cant: for specimen with a thickness below the 1/e penetration depth, the Jis and Nordtest protocols gave the same results. For specimen with a thickness above the 1/e penetration depth on the other hand, different results were obtained.

Varying the surface film resistance was found to have a significant influence on the obtained results. A lower surface film resistance resulted in a higher MBV. The biggest influence was found for the most permeable materials and for very high values of the surface film resistance.

The practical applicability of the MBV as characterising value for hygric buffering was investigated by comparing the dynamic moisture balance of a small room with each of the materials used in turns as finishing material. The MBV showed to be a good indication of the buffering capacities in the case of long term variations of the vapour production (daily variation comparable with the test protocol of the Nordtest-project) and if the MBV was determined under similar conditions as in the later application of the material (surface film resistance and specimen thickness). For short term variations the correlation between MBV and dynamic response was less. One can conclude that the closer the agreement between indoor conditions and test protocol (minimum and maximum levels of the square wave signal and the duration of the low and high relative humidity) the more reliable the MBV will be.

When comparing the theoretically determined MBV based on the moisture effusivity with the dynamically determined value with a negligible surface film resistance, a rather good agreement was found at the mean $\mathrm{RH}$ of the test protocol. The exact agreement between both values, however, was found to be situated at different $\mathrm{RH}$ for all four materials investigated. This was attributed to the non-linearity of the hygric properties.

\section{ACKNOWLEDGEMENT}

The results in this paper have been obtained within KUL OT/04/28 'Towards a reliable prediction of the moisture stress on building enclosures', funded by the KULEUVEN. This financial support is gratefully acknowledged.

\section{REFERENCES}

1. BYG DTU R-126. (2005). Moisture buffering of building materials.

2. Carslaw, H.S. and Jaeger, J.C. (1990). Conduction of heat in solids (second edition). At the Clarendon Press, Oxford, United Kingdom.

3. Clausen, G., Rode, C., Bornehag, C.-G. and Sundell, J. (1999). Dampness in buildings and health. Interdisciplinary research at the International Centre for Indoor Environment and Energy. In: Proceedings of the $5^{\text {th }}$ Symposium on Building Physics in the Nordic Countries, August 24-26 1999. Göteborg, Sweden, Vol. 2, pp. 621-627.

4. Fang, L., Clausen, G. and Fanger, P.O. (1998). Impact of temperature and humidity on the perception of indoor air quality. Indoor Air. 8: 80-90.

5. Goossens, E. (2003). Moisture transfer properties of coated gypsum. PhD-thesis TU/e, Eindhoven, The Netherlands.

6. Hens, H. (1992). Package of Climatological Data measured in Belgian Buildings, International Report T2-B-92/01, IEA, Annex 24 Heat, air and moisture transfer in Insulated Envelope Parts.

7. Hens, H. (2003), Proposal for a new Annex: Whole building heat, air and moisture response (MOIST-ENG), unpublished report, Katholieke Universiteit Leuven, Leuven, Belgium.

8. JIS A 1470-1 (2002). Test method of adsorption/desorption efficiency for building materials to regulate an indoor humidity-Part 1: Respons method of humidity.

9. Kalamees, T., Vinha, J. and Kurnitski, J. (2006). Indoor humidity loads and moisture production in lightweight timber-frame detached houses. Journal of Building Physics. 29(3): 219-246.

10. Kumaran, M.K. (1996). IEA- Annex 24: Heat, air and moisture transfer in insulated envelope parts. Final report, volume 3. Task 3: Material properties. Acco Leuven, Belgium.

11. Künzel, H.M., Kiessl, K. (1990). Bestimming des Wasserdampfdiffusionswiderstandes von mineralischen Baustoffen aus Sorptionsversuchen. Bauphysik. 12: 140-144.

12. Padfield, T. (1999). Humidity buffering of the indoor climate by absorbing walls. In: Proceedings of the $5^{\text {th }}$ Symposium on Building Physics in the Nordic Countries, August 24-26 1999. Göteborg, Sweden, Vol. 2, pp. 637-644. 
13. Peuhkuri (2003). Moisture dynamics in building envelopes. PhD-thesis, Technical University of Denmark, Copenhagen, Denmark.

14. Peuhkuri, R. and Rode, C. (2005). Using dynamic moisture loading tests for determination of moisture buffer value. International Report A41-T2-Dk-05-1, IEA-Annex 41 Whole building heat, air and moisture response.

15. Peuhkuri, R., Rode C. and Hansen, K.K. (2004). Moisture buffer capacity of different insulation materials. In: Proceedings of Performance of Exterior Envelopes of Whole Buildings XI, December 5-10 2004. Clearwater Beach, Florida, CD-rom.

16. Rode, C. and Grau, K. (2002). Integrated calculation of hygrothermal conditions of buildings. In: Proceedings of the $6^{\text {th }}$ Symposium on Building Physics in the Nordic Countries, Trondheim, Norway, Vol. 1, pp. 23-30.

17. Rode, C., Mitamura, T., Schultz, J. and Padfield, T. (2002). Test cell measurements of moisture buffer effects. In: Proceedings of the $6^{\text {th }}$ Symposium on Building Physics in the Nordic Countries, Trondheim, Norway, Vol. 2, pp. 619-626.

18. Rode, C., Salonvaara, M., Ojanen, T., Simonson, C. And Grau, K. (2003). Integrated hygrothermal analysis of ecological buildings. In: Research in Building Physics, Leuven, Belgium, pp. 859-868.

19. Rode, C., Peuhkuri, R., Hansen, K.K., Time, B., Svennberg, K., Arfvidsson, J. and Ojanen, T. (2005). Moisture buffer value of materials in buildings. In Proceedings of the $7^{\text {th }}$ Symposium on Building Physics in the Nordic Countries, June 13-15 2005. Reykjavik Iceland, Vol. 1, pp. 108-115.

20. Seldbauer, K. and Krus, M. (2003). A new model for mould prediction and its application in practice. In: Research in Building Physics, Leuven, Belgium, pp. 921-927.

21. Simonson, C.J., Salonvaara, M. and Ojanen, T. (2002) Humidity, comfort and air quality in a bedroom with hygroscopic wooden structures. In: Proceedings of the $6^{\text {th }}$ Symposium on Building Physics in the Nordic Countries, Trondheim, Norway, Vol. 2, pp. 743-750.

22. Simonson, C.J., Salonvaara, M. and Ojanen, T. (2004). Heat and mass transfer between indoor air and a permeable and hygroscopic building envelope : part I - Field measurements. Journal of Thermal Envelope and Building Science. 28(1): 63-101.

23. Simonson, C.J., Salonvaara, M. and Ojanen, T. (2004). Heat and mass transfer between indoor air and a permeable and hygroscopic building envelope : part II - Verification and numerical studies. Journal of Thermal Envelope and Building Science. 28(2): 161-185.

24. Wadsö, L. (1993). Studies of water vapour transport and sorption in wood. PhD-thesis Lund University, Lund, Sweden. 


\section{TABLES}

Table 1.- $\quad$ The parameters for the analytic fit of the sorption isotherm and water vapour resistance factor for the different materials. In addition the calculated $1 / e$ and $1 \%$ penetration depths at $50 \% R H$ are given.

\begin{tabular}{lcccc}
\hline & $\begin{array}{c}\text { wood fibre board } \\
\text { (WFB) }\end{array}$ & $\begin{array}{c}\text { plywood } \\
(\mathrm{PW})\end{array}$ & $\begin{array}{c}\text { cellular concrete } \\
(\mathrm{ACC})\end{array}$ & $\begin{array}{c}\text { gypsum plaster } \\
(\mathrm{GP})\end{array}$ \\
\hline sorption isotherm & & & & 30.36 \\
$\mathrm{~W}_{\text {sat }}$ & 150 & 200 & 258 & -69.48 \\
$\mathrm{~m}$ & -91.41 & -80.58 & -208312.96 & 1.800 \\
$\mathrm{n}$ & 1.416 & 1.337 & 1.317 & 0.268 \\
\hline vapour resistance factor & & & & 0.0 \\
$\mathrm{a}$ & 0.085 & 0.005 & 0.100 & - \\
$\mathrm{b}$ & $2.47^{\star} 10^{-3}$ & $5.46^{\star} 10^{-6}$ & $1.47^{\star} 10^{-4}$ & 3.3 \\
$\mathrm{C}$ & 5.0 & 10.5 & 1.521 & 13.98 \\
\hline 1/e penetration depth & 0.687 & 0.125 & & \\
at 50\% RH (cm) & & & 7.005 & \\
\hline 1 \% penetration depth & 2.890 & 0.550 & & \\
at 50\% RH (cm) & & & &
\end{tabular}

Table 2.- $\quad$ Influence of the specimen thickness on the obtained MBV for the four materials investigated. The values marked in light grey are those determined on specimen for which the thickness is less than the 1/e penetration depth.

\begin{tabular}{ccccc}
\hline $\begin{array}{c}\text { thickness } \\
(\mathrm{cm})\end{array}$ & $\begin{array}{c}\text { wood fibre board } \\
\text { (WFB) }\end{array}$ & $\begin{array}{c}\text { plywood } \\
\text { (PW) }\end{array}$ & $\begin{array}{c}\text { cellular concrete } \\
(\text { ACC) }\end{array}$ & $\begin{array}{c}\text { gypsum plaster } \\
(\mathrm{GP})\end{array}$ \\
\hline 8-16 hour loading protocol (Nordtest-project) \\
\hline 3 & 1.86 & 0.69 & 0.81 & 0.94 \\
1 & 1.85 & 0.69 & 0.82 & 0.91 \\
0.5 & 1.92 & 0.69 & 0.61 & 0.43 \\
\end{tabular}

Table 3.- $\quad$ Influence of the time scheme on the obtained MBV for two different thicknesses $(1 \mathrm{~cm}$ and $10 \mathrm{~cm}$ ) of the four materials investigated. The values marked in light grey are those determined on specimen for which the thickness is less than the 1/e penetration depth.

\begin{tabular}{ccccccccc}
\hline & $\begin{array}{c}\text { wood fibre board } \\
\text { (WFB) }\end{array}$ & \multicolumn{2}{c}{$\begin{array}{c}\text { plywood } \\
\text { (PW) }\end{array}$} & \multicolumn{2}{c}{$\begin{array}{c}\text { cellular concrete } \\
(\text { ACC) }\end{array}$} & \multicolumn{2}{c}{$\begin{array}{c}\text { gypsum plaster } \\
(\mathrm{GP})\end{array}$} \\
\hline thickness (cm) & 10 & 1 & 10 & 1 & 10 & 1 & 10 & 1 \\
\hline Nordtest-scheme & 1.86 & 1.92 & 0.69 & 0.69 & 0.81 & 0.61 & 0.94 & 0.43 \\
JIS-scheme & 3.09 & 3.16 & 1.08 & 1.08 & 1.29 & 0.66 & 1.55 & 0.44 \\
\hline
\end{tabular}

Table 4.- $\quad$ Influence of the surface film resistance on the obtained $M B V$ (in $\mathrm{g} / \mathrm{m}^{2} . \% R H$ ) for the four materials investigated.

\begin{tabular}{ccccc}
\hline $\begin{array}{c}\text { surface resistance } \\
{ }^{1} 10^{7}\left(\mathrm{~m}^{2} \mathrm{sPa} / \mathrm{kg}\right)\end{array}$ & $\begin{array}{c}\text { wood fibre board } \\
(\text { WFB })\end{array}$ & $\begin{array}{c}\text { plywood } \\
(\mathrm{PW})\end{array}$ & $\begin{array}{c}\text { cellular concrete } \\
(\text { ACC })\end{array}$ & $\begin{array}{c}\text { gypsum plaster } \\
(\mathrm{GP})\end{array}$ \\
\hline 33 & 0.55 & 0.47 & 0.56 & 0.61 \\
10 & 1.55 & 0.64 & 0.75 & 0.86 \\
5 & 1.86 & 0.69 & 0.82 & 0.94 \\
3.3 & 1.99 & 0.71 & 0.83 & 0.97 \\
1 & 2.20 & 0.74 & 0.86 & 1.01 \\
negligible (0.0033) & 2.31 & 0.76 & 0.89 & 1.03 \\
\hline
\end{tabular}


Table 5.- $\quad$ Amplitude of the relative humidity in the room in the case of long term variations and variable thickness of the finishing layer $(1 \mathrm{~cm}$ or $10 \mathrm{~cm})$. As a reference also the MBV determined according to the Nordtest-protocol on specimen of 1 and $10 \mathrm{~cm}$ is given for the different materials.

\begin{tabular}{lccccc}
\hline & $\begin{array}{c}\text { no absorbing } \\
\text { material }\end{array}$ & with WFB & with PW & With ACC & with GP \\
\hline MBV Nordtest 1cm/10cm & - & $1.92 / 1.86$ & $0.69 / 0.69$ & $0.61 / 0.81$ & $0.43 / 0.94$ \\
\hline $\begin{array}{l}\text { Amplitude by a material } \\
\text { layer thickness of } 10 \mathrm{~cm}\end{array}$ & 18.5 & 7.0 & 11.8 & 10.6 & 10.0 \\
$\begin{array}{l}\text { Amplitude by a material } \\
\text { layer thickness of } 1 \mathrm{~cm}\end{array}$ & 18.5 & 6.8 & 11.8 & 12.6 & 14.7 \\
\hline
\end{tabular}

Table 6.- $\quad$ Amplitude of the relative humidity in the room in the case of short term variations and variable thickness of the finishing layer $(1 \mathrm{~cm}$ or $10 \mathrm{~cm})$. As a reference also the $M B V$ determined according to the Nordtest-protocol on specimen of 1 and $10 \mathrm{~cm}$ is given for the different materials.

\begin{tabular}{lccccc}
\hline & $\begin{array}{c}\text { no absorbing } \\
\text { material }\end{array}$ & with WFB & with PW & With ACC & with GP \\
\hline MBV Nordtest $1 \mathrm{~cm} / 10 \mathrm{~cm}$ & - & $1.92 / 1.86$ & $0.69 / 0.69$ & $0.61 / 0.81$ & $0.43 / 0.94$ \\
\hline $\begin{array}{l}\text { Amplitude by a material } \\
\text { layer thickness of } 10 \mathrm{~cm}\end{array}$ & 14.0 & 6.2 & 9.4 & 8.6 & 8.2 \\
$\begin{array}{l}\text { Amplitude by a material } \\
\text { layer thickness of } 1 \mathrm{~cm}\end{array}$ & 14.0 & 6.2 & 9.4 & 8.5 & 8.4 \\
\hline
\end{tabular}




\section{FIGURE CAPTIONS}

Figure 1. Sorption isotherm (left) and water vapour resistance factor (right) for the four different materials investigated: wood fibreboard, plywood, aerated cellular concrete and gypsum plaster. The dots correspond to the measured values, the continuous lines to the analytic fits used in the numerical simulations.

Figure 2. Influence of the time scheme on the obtained MBV for wood fibreboard and gypsum plaster in the case of specimen with a thickness of $10 \mathrm{~cm}$ (top) and $1 \mathrm{~cm}$ (bottom). The continuous line corresponds to the loading scheme as proposed in the Nordtest-project, the dotted line to the loading scheme of the Japanese Industrial Standard.

Figure 3. Influence of the surface film resistance on the hygric response of the specimen (and hence on the MBV) as numerically predicted for wood fibre board.

Figure 4. Evolution of the relative humidity in the room with time for the daily variations in case no absorbing material is present (bold continuous line) and if $60 \mathrm{~m}^{2}$ of the walls is finished with $10 \mathrm{~cm}$ of wood fibreboard (circles), plywood (triangles), cellular concrete (squares) or gypsum plaster (diamonds).

Figure 5. Evolution of the relative humidity in the room for the daily variations, with compared to Figure 4 the thickness of the absorbing materials limited to $1 \mathrm{~cm}$.

Figure 6. Amplitude of the relative humidity in the room in case of daily variations plotted as a function of the moisture buffer value as determined according to the Nordtest test-protocol on $10 \mathrm{~cm}$ thick specimen (left), according to the Nordtest-protocol but on specimen with the same thickness as applied in the room (middle) and as determined according to the Japanese Industrial Standard (right) .

Figure 7. Evolution of the relative humidity in the room with time for short term variations in case no absorbing material is present (bold continuous line) and if $60 \mathrm{~m}^{2}$ of the walls is finished with $10 \mathrm{~cm}$ of wood fibreboard (circles), plywood (triangles), cellular concrete (squares) or gypsum plaster (diamonds).

Figure 8. Evolution of the relative humidity in the room for short term variations, with compared to Figure 7 the thickness of the absorbing materials limited to $1 \mathrm{~cm}$.

Figure 9. Amplitude of the relative humidity in the room in case of short term variations plotted as a function of the moisture buffer value as determined according to the Nordtest test-protocol on $10 \mathrm{~cm}$ thick specimen (left), according to the Nordtest-protocol but on specimen with the same thickness as applied in the room (middle) and as determined according to the Japanese Industrial Standard (right) .

Figure 10. Dynamically determined MBV (straight lines) versus steady state derived MBV (continuous functions of $\mathrm{RH}$ ) for the four materials under 
the Nordtest protocol. The RH of the intersection points between both is indicated with the arrows.

Figure 11. Moisture accumulation plotted versus square root of time for gypsum plaster under the Nordtest protocol, for specimen thicknesses of 10 and $1 \mathrm{~cm}$, and negligible and $5^{\star} 10^{7} \mathrm{~m}^{2} \mathrm{sPas} / \mathrm{kg}$ surface film resistances. 
FIGURE 1.
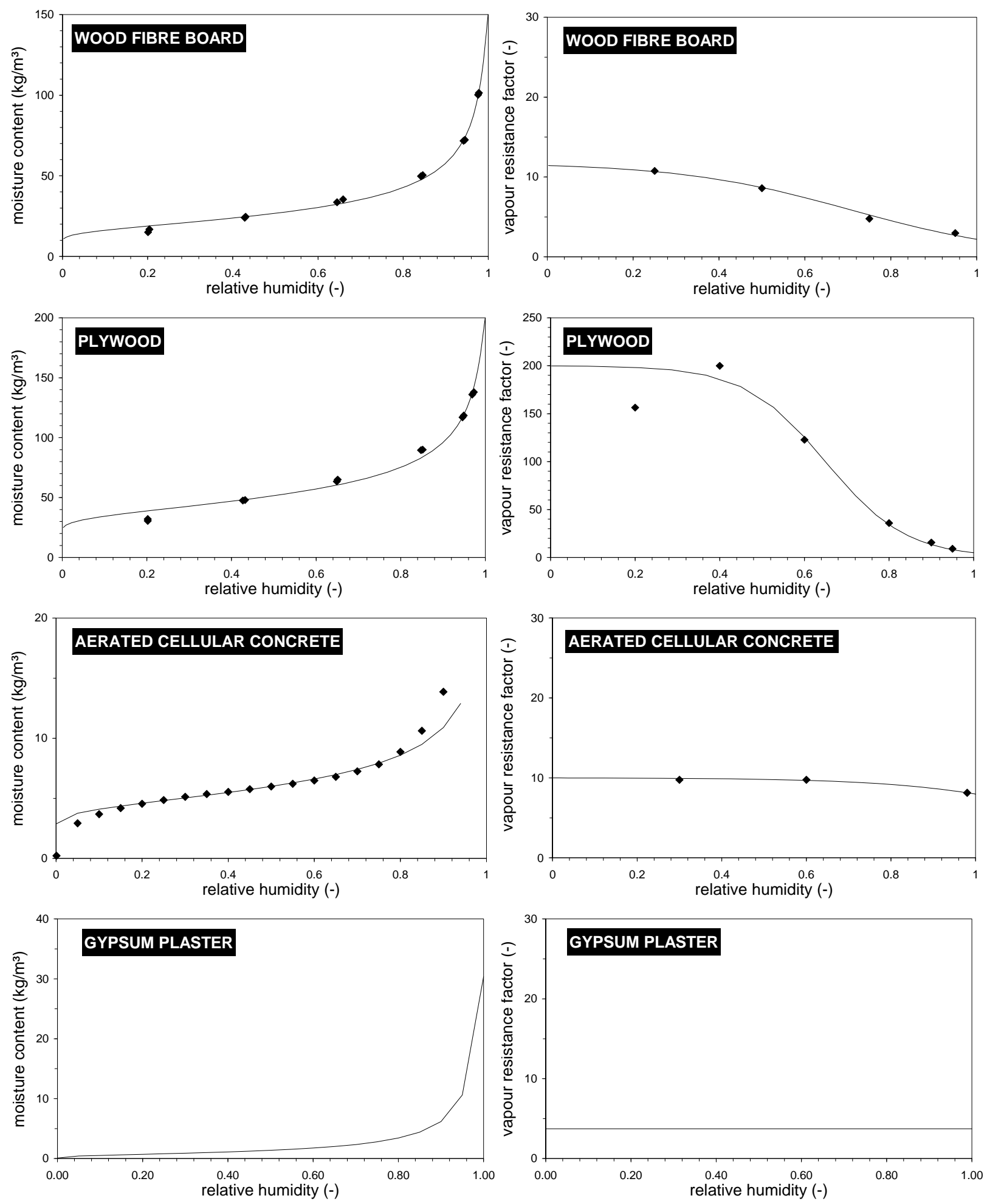
FIGURE 2.
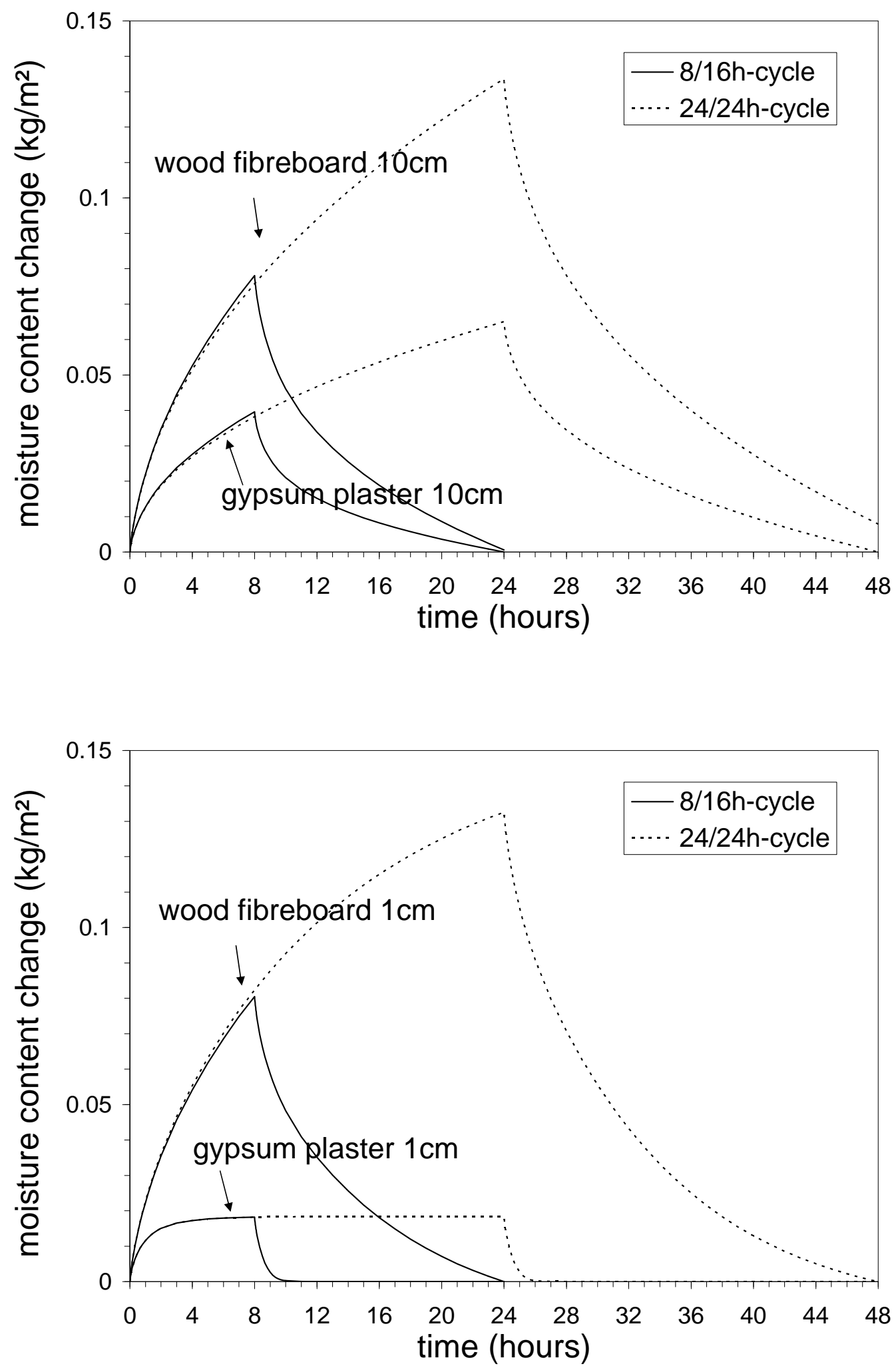


\section{FIGURE 3.}

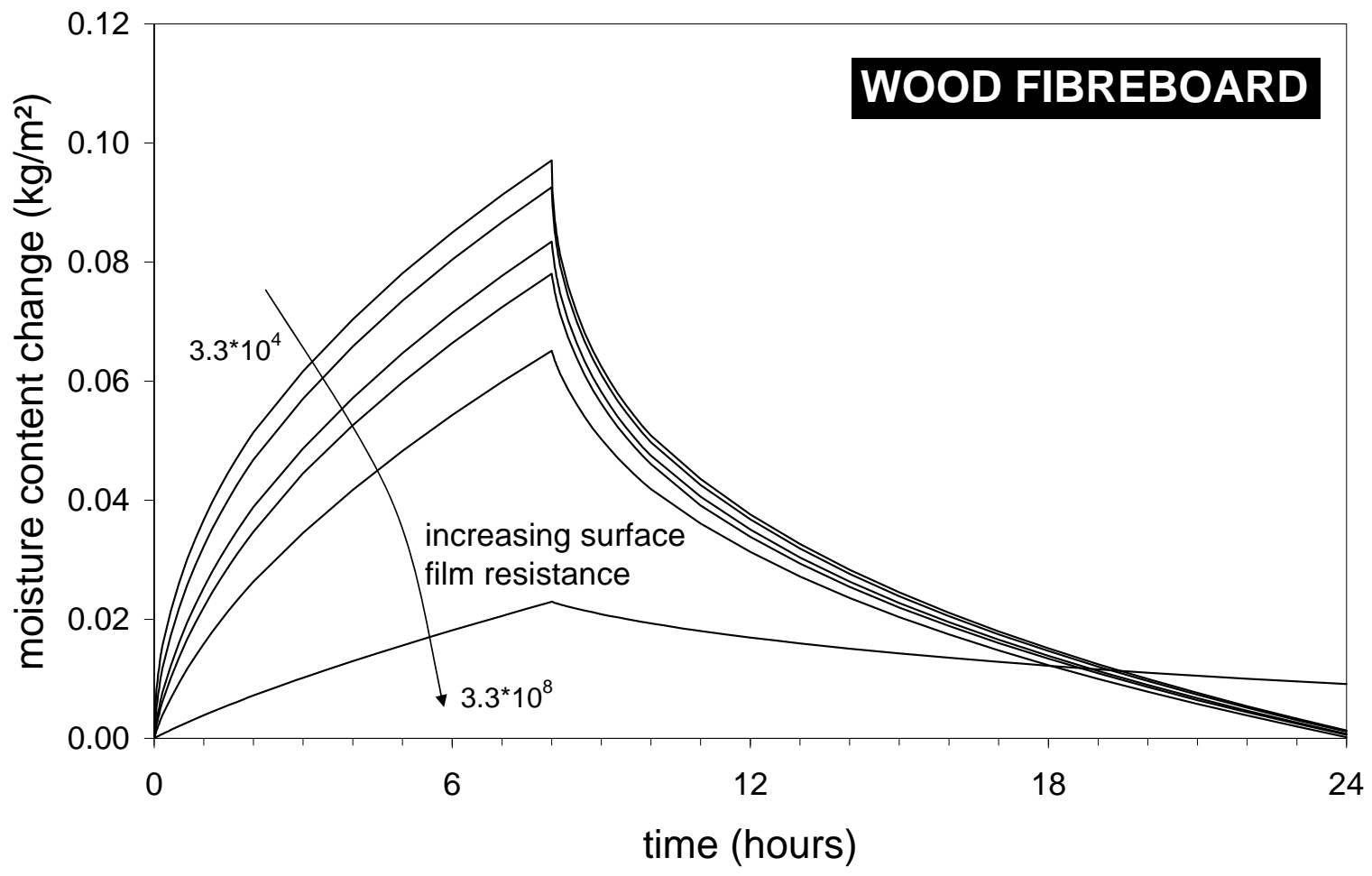


FIGURE 4.

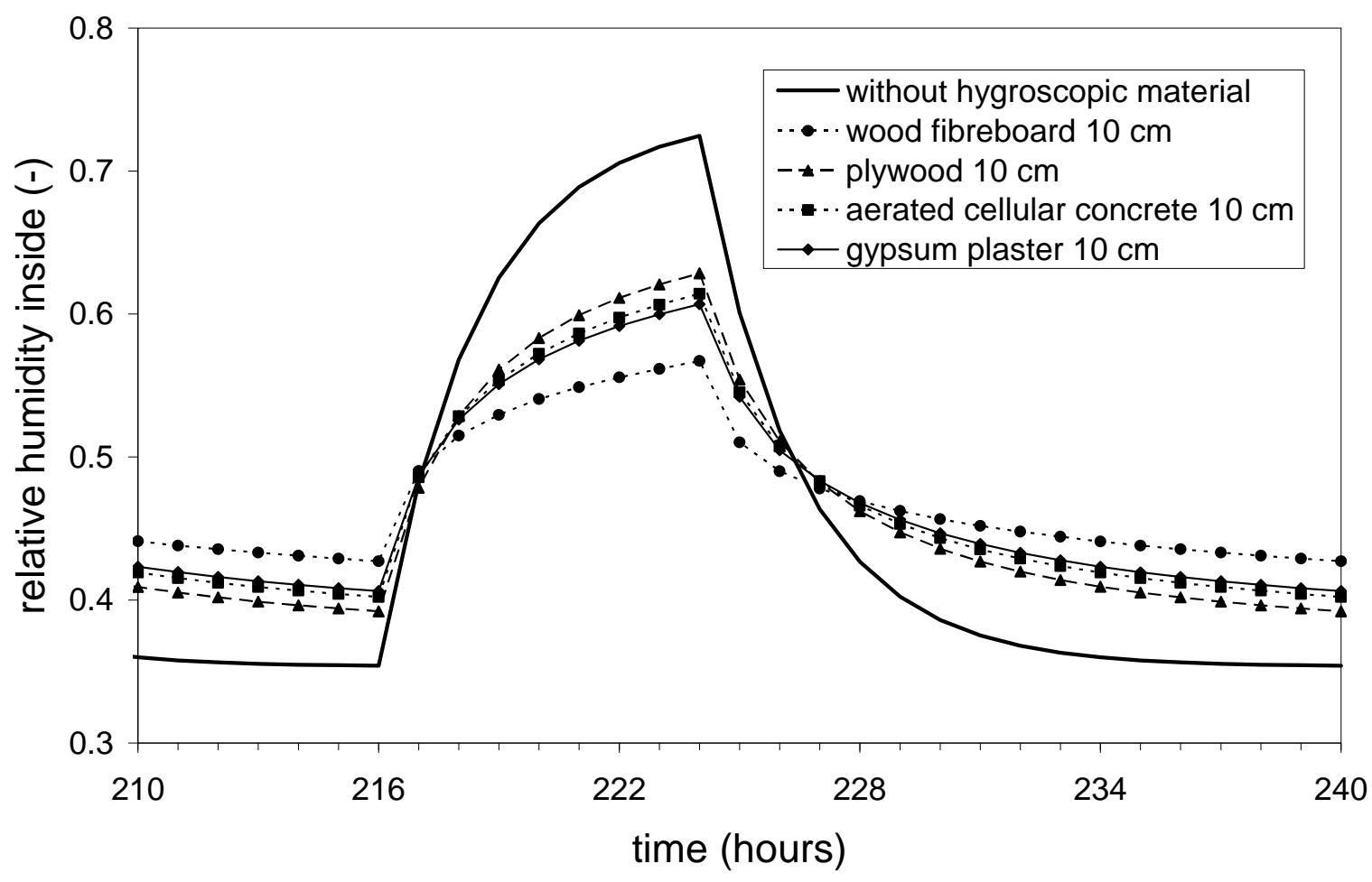

FIGURE 5.

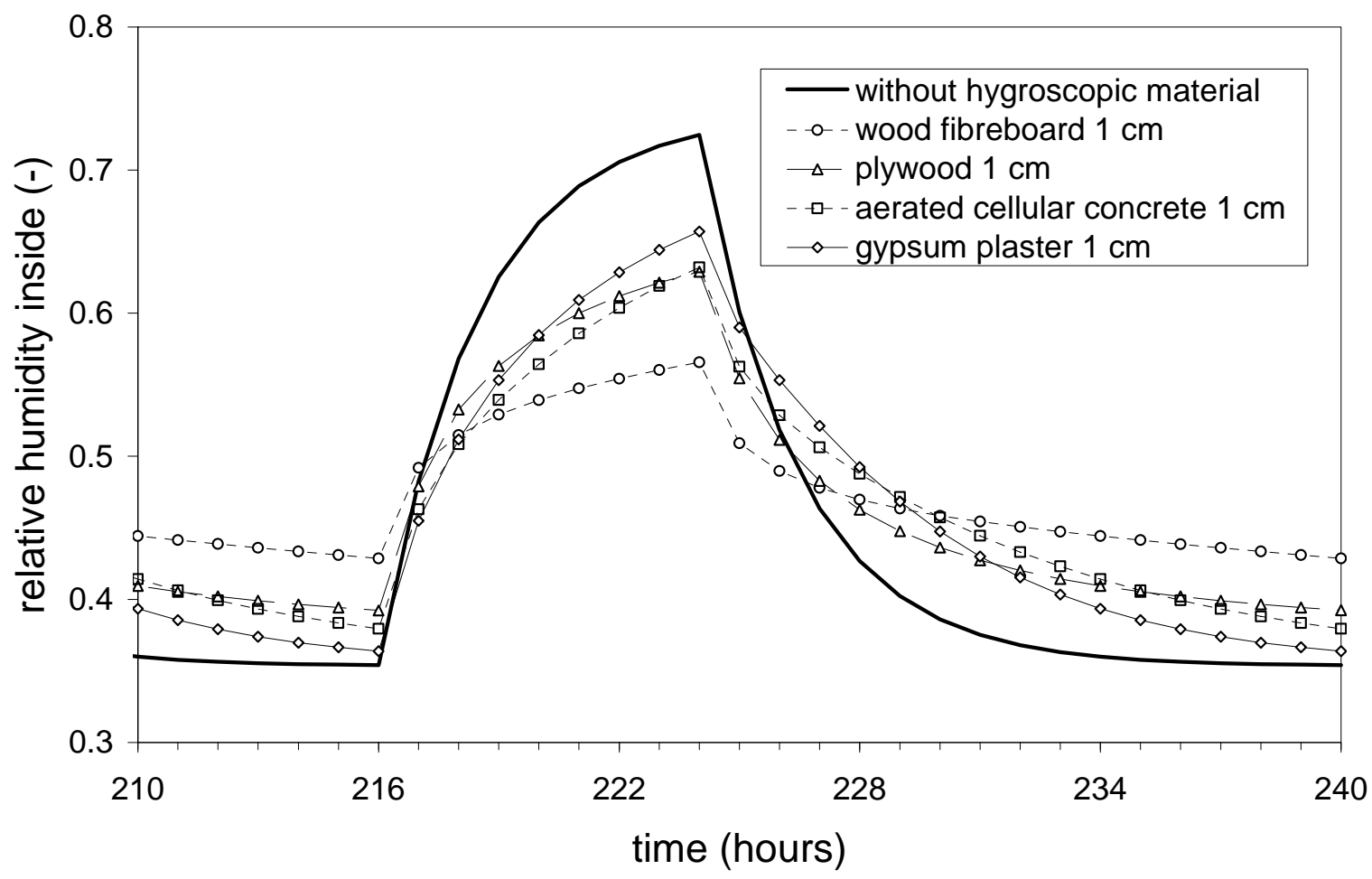


FIGURE 6.
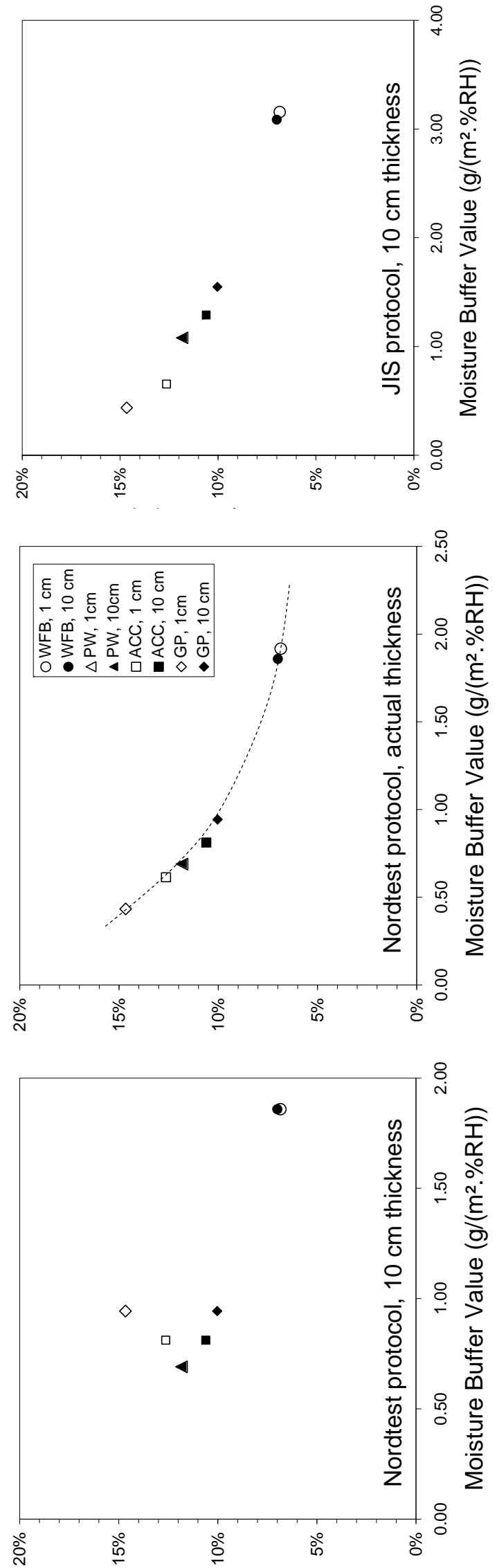

(\%) әрп!!|dure Hप 
FIGURE 7.

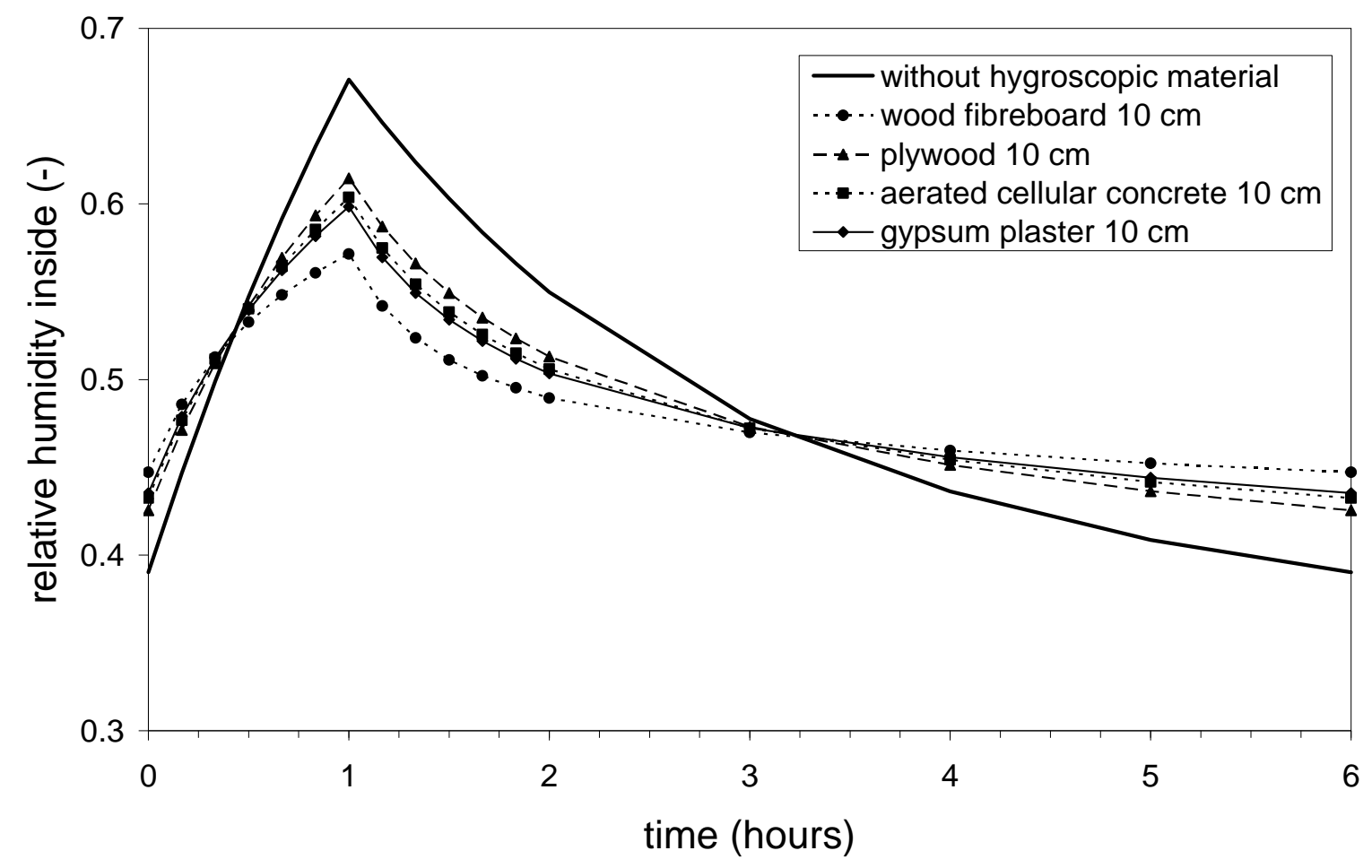

FIGURE 8.

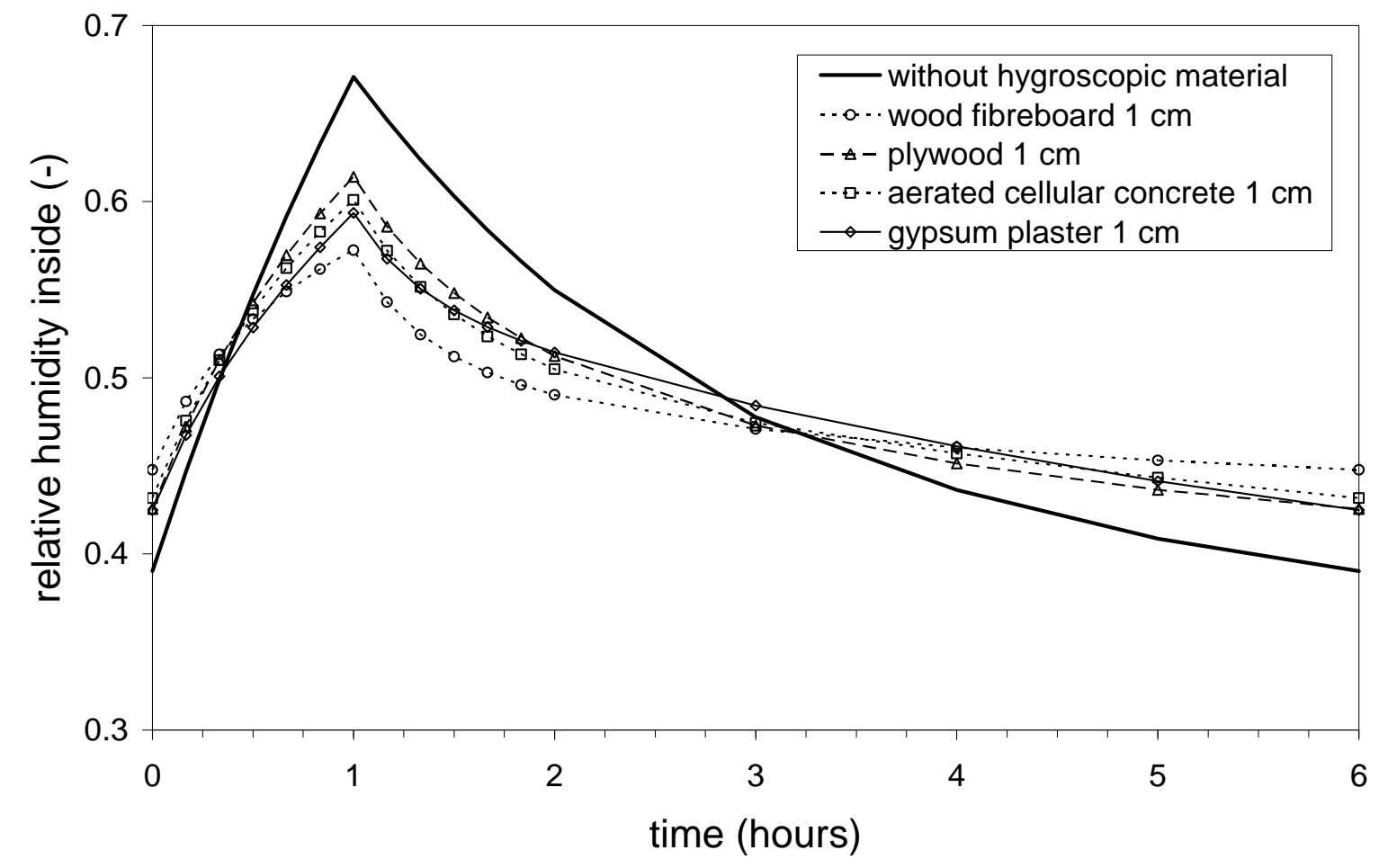


FIGURE 9.
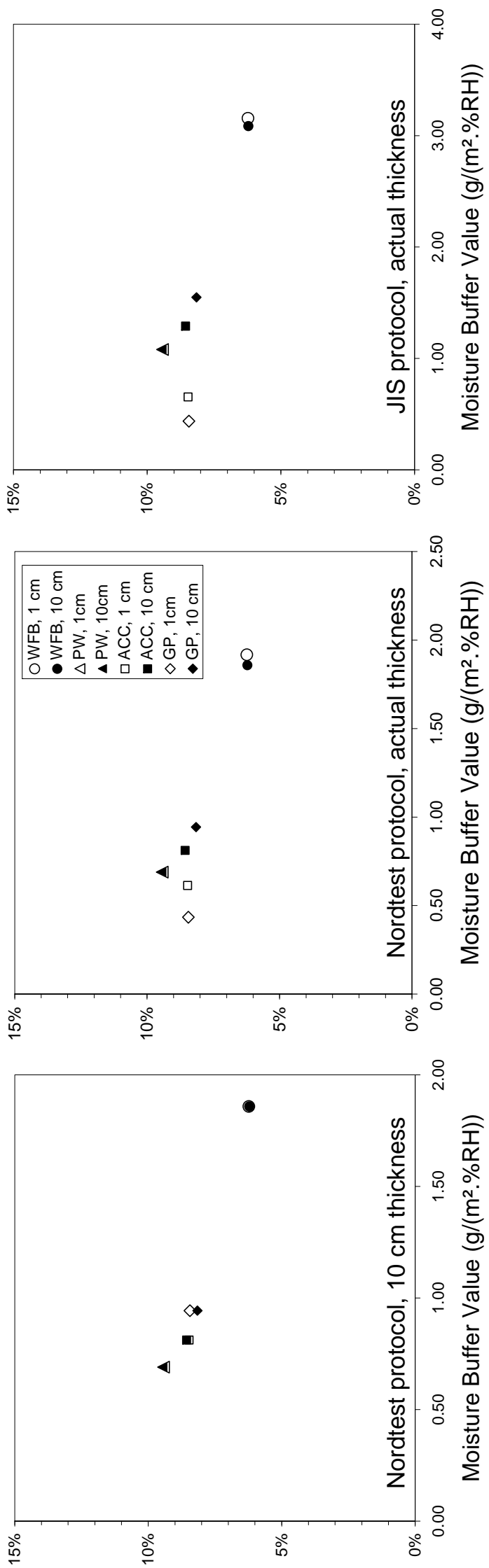

(\%) әрпџ!|dure Hy 
FIGURE 10.

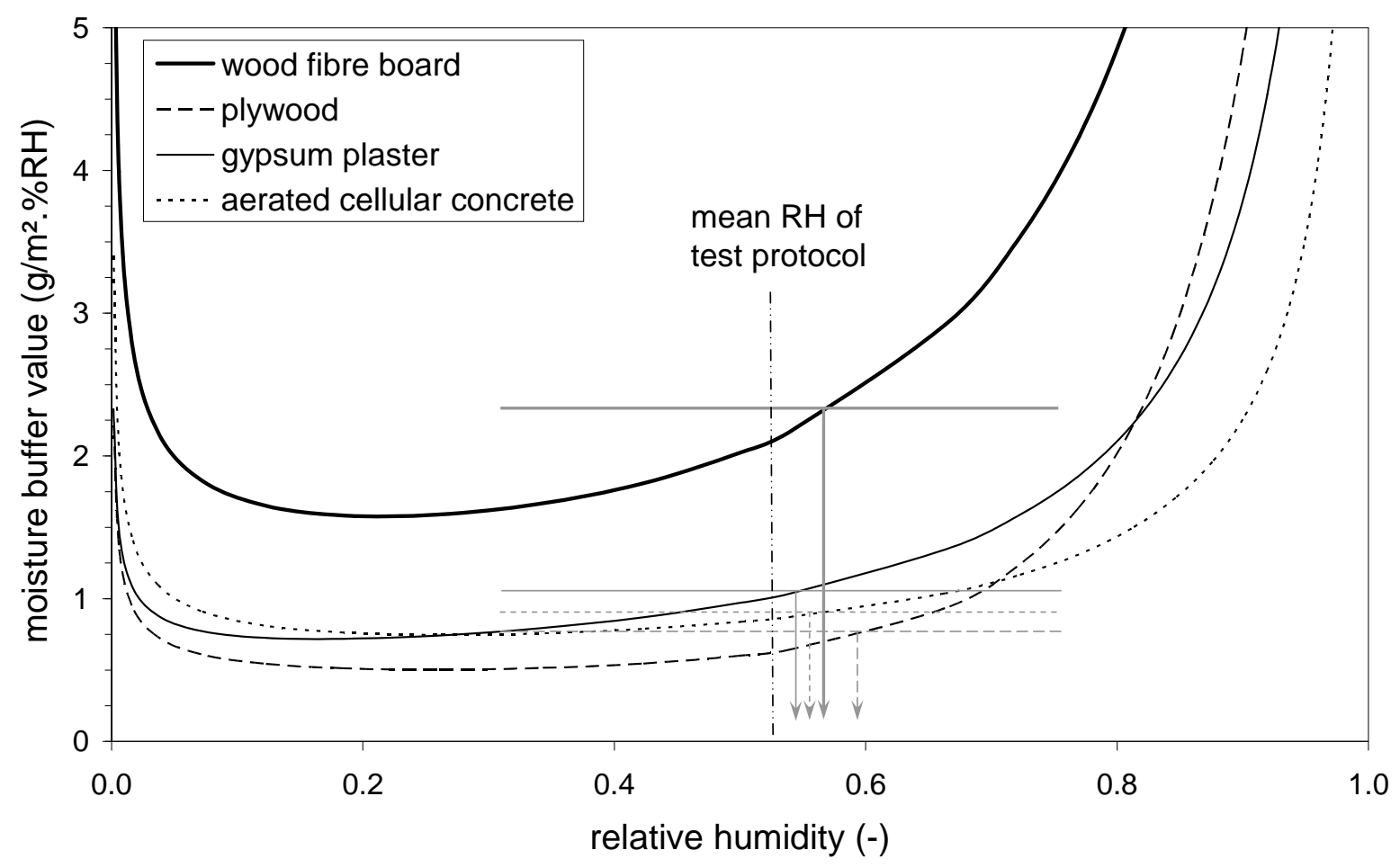

FIGURE 11.

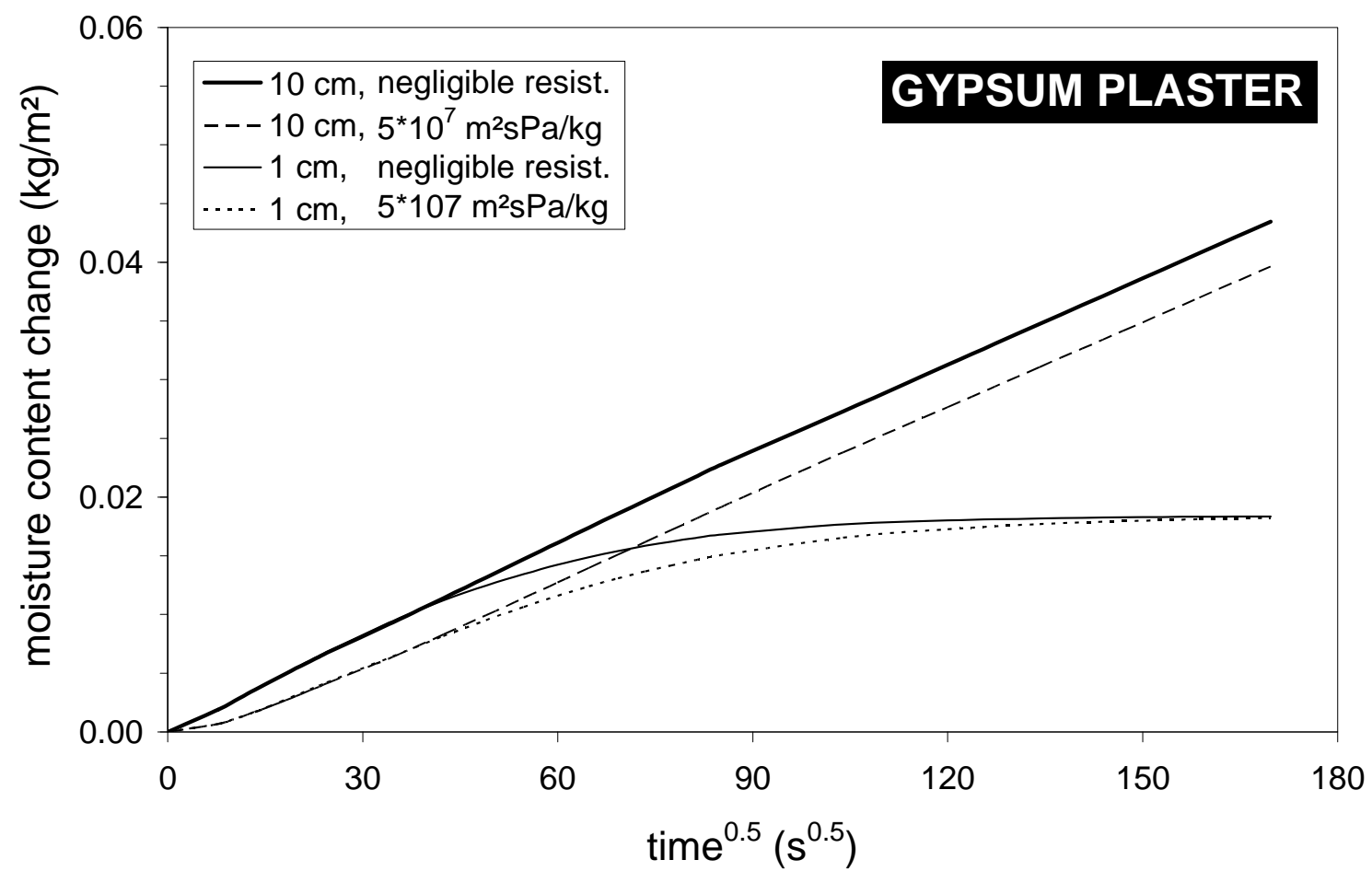

